\title{
Proposed specifications of a mobile operating room for far-forward surgery
}

\author{
CPO John Leasiolagi \\ PO2 Troy Holton \\ LCol Kate Doyle, MD
}

Sgt Laura Parkinson, LPN

Capt (Navy) Raymond Kao, MD

LCol Vivian C. McAlister, MB

Accepted Oct. 3, 2018

\section{Correspondence to: \\ V. McAlister \\ University Hospital \\ Western University \\ London ON N6A 5A5 \\ vmcalist@uwo.ca}

DOI: $10.1503 /$ cjs. 014718

\section{SUMmaRY}

Provision of initial surgery to casualties within one hour of injury is associated with better survival. Where evacuation options are limited, surgery within the "golden hour" may have to occur close to the point of injury. Interventions close to the point of injury are limited by the adverse environment. Far-forward surgery has a long history going back to Dominique Larrey of the Napoleonic Army. We reviewed previous reports and used our own experience of farforward surgery to describe the specifications of the ideal mobile operating room that would address some of these environmental barriers.

n 2009, United States Secretary of Defence Robert M. Gates mandated prehospital helicopter transport of critically injured combat casualties in 60 minutes or less. This directive, the goal of which was to allow trauma surgery to take place within the "golden hour," was determined to have resulted in a marked reduction in the case fatality rate. ${ }^{1}$ A re-examination of the data confirmed the importance of rapid transport of casualties to a forward surgery facility. ${ }^{2}$ During recent conflicts in Afghanistan and Iraq, casualty evacuation was provided heroically by the Blackhawk squadrons of the US military, known colloquially by the Vietnam War era callsign "Dustoff." Role 2 hospitals were designed and deployed to provide rapid access to damage-control surgery. ${ }^{3}$ The success of casualty evacuation allowed medical planners to concentrate first on providing high-value on-site care through the tactical combat casualty care program. ${ }^{4}$ Recent conflicts involved an asymmetric balance between opponents, where the conventional side retained control of the air and the ability to complete casualty evacuation within the mandatory period. There is concern that rapid casualty evacuation may not be possible in future conflicts because of remoteness, lack of a secure zone or loss of air superiority. Advanced resuscitation, which had been added to the concept of damage control, is more amenable than surgery to being pushed forward toward the point of injury. ${ }^{5}$ Although damage-control resuscitation should augment initial care, it is not a substitute for trauma surgery. Far-forward surgery has been developed as a means to bring surgical services closer to the point of injury so that the casualty may have access to damage-control surgery within the golden hour. ${ }^{6}$

Surgeons have accompanied soldiers to war since ancient times. Illustrations from the time mainly show "first-aid" procedures being performed. Clearly, some patients with serious injuries survived. Alexander the Great and his father Philip II of Macedon both endured an astounding array of injuries during combat. The surgeon Kritoboulos was acknowledged by Pliny the Elder for his skill in treating Philip in the field. Philip was injured by either an arrow or a spear that destroyed his right eye, crushing the orbital bones and forehead. The severity of the injury was proven recently when Philip's ossuary was discovered. However, most injured soldiers were left on the field of combat until hostilities ceased and care was rendered only by permission of the victor. This was the situation that caused Henri Durant to found the Red 
Cross in 1863. Around the same time, Maj Jonathan Letterman, medical director of the Army of the Potomac, developed the first modern system of field care, which included forward first aid/triage, ambulance evacuation and field hospital care. His system has endured as a scheme of military medicine to this day.

The concept of casualty evacuation by ambulance goes back to the Napoleonic army. Less well known is that Dominique Jean Larrey initially proposed that the "ambulance volante" would bring surgeons and their kit to the point of injury, where surgery would be performed. The system popularized by Letterman during the American Civil War, and continued today, emphasizes first aid and rapid casualty evacuation. Innovations in the First World War included novel means to transport casualties, such as using barges on canals and improvised rail lines to cross mud; these methods were needed because of the huge numbers of wounded being sent back from an almost stationary front line. ${ }^{7,8}$ In the Italian and Western European campaigns of the Second World War, rapidly moving front lines made it difficult for hospitals to keep up. Surgical teams resorted to operating from the back of ambulances. Maj Angus D. McLachlin, later head of surgery at the Western University, was seconded in 1944 from the No. 10 Canadian General Hospital to a mobile British surgical unit that moved with the advancing troops. ${ }^{9}$ Oaths of secrecy have resulted in very little information being available from these units. At the same time, the United States Army adapted ambulances for specialized purposes, such as dentistry, radiology and laboratory services. With the help of General Motors, "mobile surgical trucks" were built on a regular 2.5 ton ambulance $6 \times 6$ chassis, which, with a trailer, carried a tent, power, lights and equipment to run two operating tables. ${ }^{10}$ Again, little information is available regarding their use, and no examples are known to have survived. In 2010, the United States Marine Corps partnered with the Oshkosh Corporation to design a mobile trauma bay by attaching a containerized unit to an armoured tractor trailer. It was deployed briefly in Afghanistan to provide damage-control resuscitation in a forward position. ${ }^{11}$

We recently improvised a mobile operating room using materials available in theatre. The mobile operating room was initially intended to be part of a multivehicle, highly mobile, forward command and control centre capable of displacing and following in trace of manoeuvring combatant elements. The mobile command centre concept was born out of analysis of a transient operational requirement that called for closer proximity of support functions for manoeuvring elements. It was not meant to be a longterm, enduring mission. The initial model included several security and personnel vehicles task-organized around a command vehicle and a mobile casualty collection point (CCP). The mobile CCP's sole mission was to provide closer surgical services, essentially extending the golden hour of a distant Role 2 facility. As the date of execution approached and the mobile command centre readied to deploy, the requirement for forward command and control dissolved, leaving the extension of the golden hour as the sole mission of the forward unit. A 20-foot containerized housing unit (CHU) and a generator fixed to an armoured tractor trailer (Fig. 1), which were initially

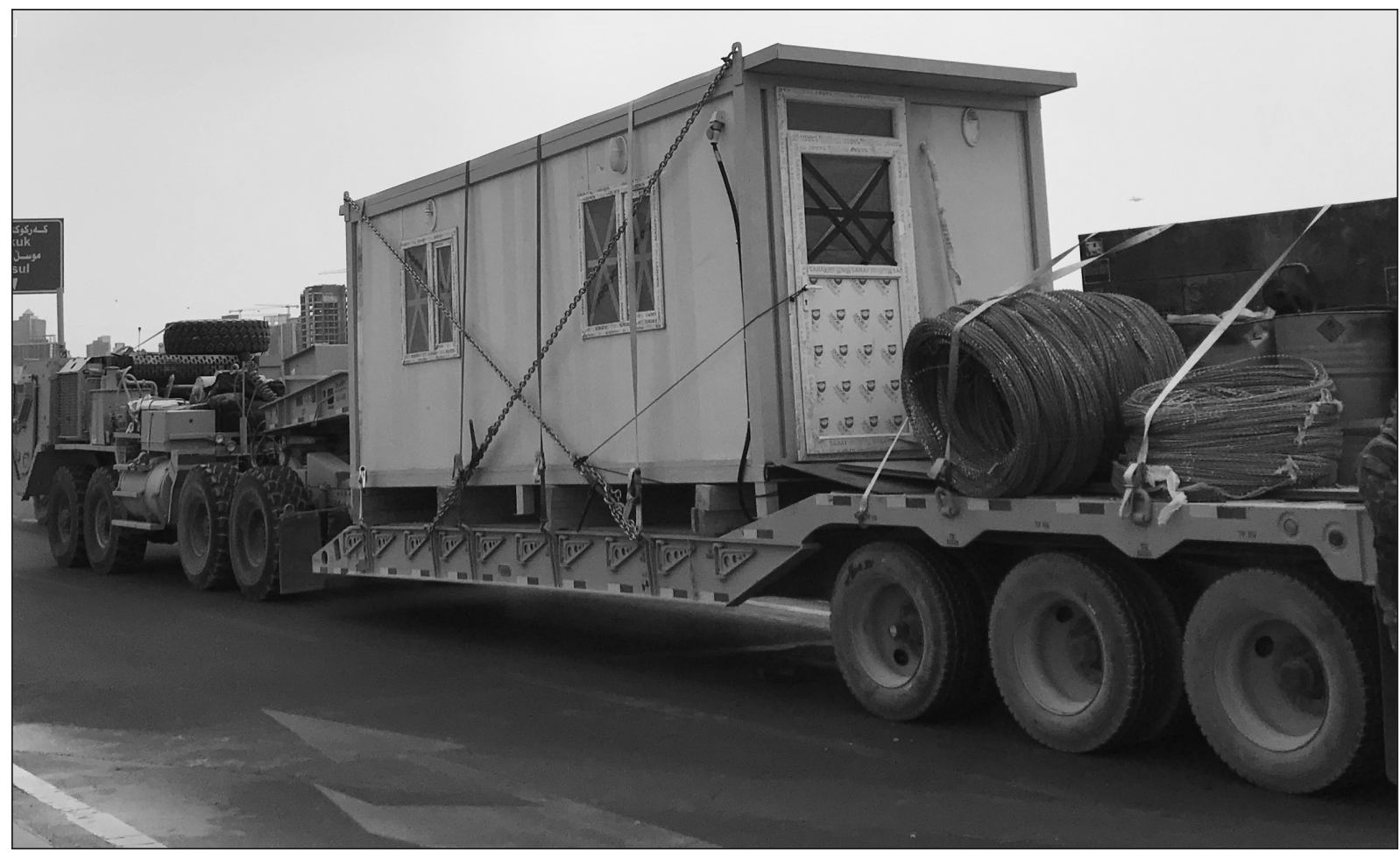

Fig. 1. Containerized housing unit (operating room) and generator fixed to an armoured tractor trailer. 
meant to house the mobile operations centre, were repurposed as a mobile operating room. Equipment from the mobile surgical resuscitation team was used to stock the operating room. ${ }^{6} \mathrm{~A}$ conventional stretcher on saw horses was used as the operating table. A special mattress and arm boards were constructed for patient comfort and to facilitate surgery. A small table-top sterilizer and a water distiller were placed in the corner of the CHU. Roll bag hangers were made to allow for easy rapid access to equipment (Fig. 2). All personal kit, as well as operating room supplies, were packed in the CHU for road moves. Personnel travelled in mine-resistent armoured personnel carriers (APC) rather than in the mobile operating room. The armoured tractor trailer was capable of negotiating gravel roads, but rough terrain would have been prohibitive (Fig. 3). Multiple moves were made during deployment of the mobile operating room with a set-up/pack-up time of less than one hour.

Using lessons learned from this less-than-ideal improvised solution, we have developed a proposed list of specifications for a mobile operating room. The vehicle should be based on an APC rather than a conventional ambulance or transport trailer. Although it should be capable of carrying the operating room personnel, their personal kit and stock for initial surgeries, operating room resupply should be carried elsewhere. This will allow the mobile operating room to move with the combat element to a CCP close to the conflict and be ready for immediate use. The APCs already have air and climate control, which will facilitate surgery in extreme environments.

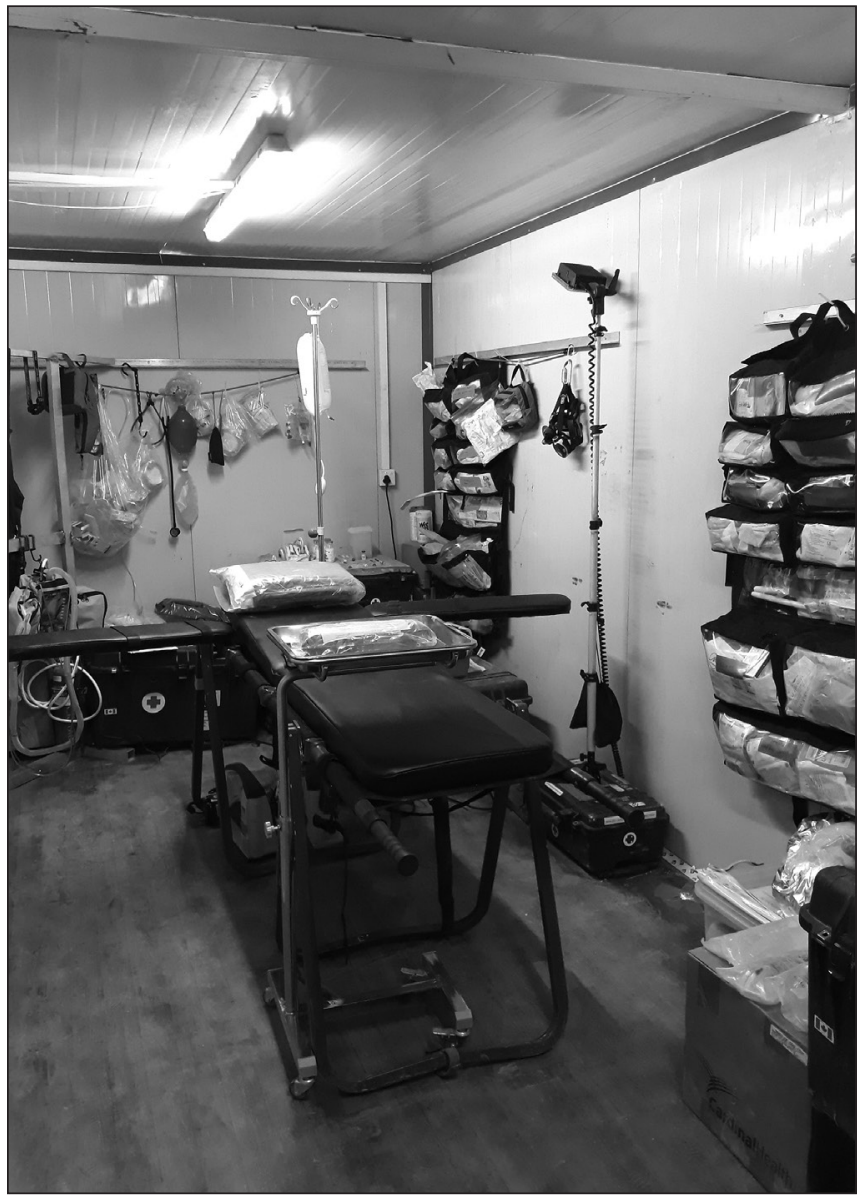

Fig. 2. Operating room inside containerized housing unit.

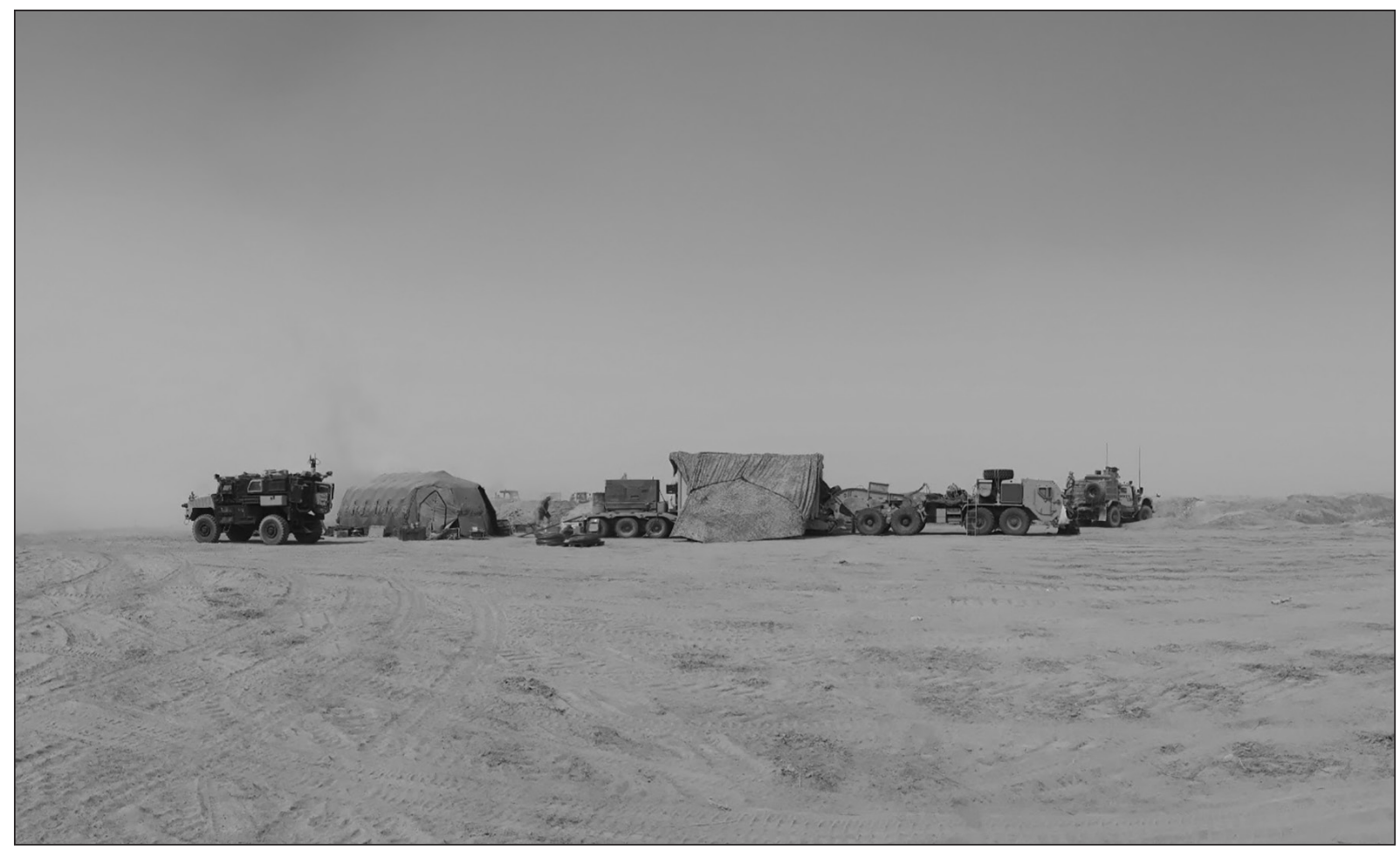

Fig. 3. Mobile operating room, under camouflage netting, set up in defended casualty collection point. 
The mobile operating room should be designed and deployed to augment the CCP, not to try to replace its resuscitation and evacuation capabilities. It would be of an additional benefit if communication systems within the vehicle were capable of video-link to allow for telementoring. The principle limitation to current APC platforms is space within the working section. Seats for personnel transport will need to fold or be removed. The working cabin requires a drainage system to permit cleaning of the floor. Clean water storage is probably best placed on the exterior of the vehicle, but it must be plumbed to the working section. Equipment and supplies for anesthesia, surgery and the operating room should be stored in a specially designed space-saving way that allows for use within the vehicle or for removal so that the operating room can be set up in a tent or room of opportunity, which would be the preference if it was available. All equipment should be battery-powered. Surgeons' battery-operated head lamps are reasonable alternatives to conventional operating lights, which would be difficult to design for the confined space of an APC and are too bulky for mobile use. The power system of the vehicle should be capable of recharging operating room equipment while moving or standing still. Conventional operating tables and radiography machines have no place in a mobile operating room because they are heavy and cumbersome. Portable ultrasonography has replaced radiography in acute trauma care. Combat stretchers supported on devices at table height make for versatile operating tables. However, the concave nature of stretchers make it difficult to complete advance trauma life support protocols, provide anesthesia and perform surgery. A hard-backed surgical foam mattress can be designed to lift the patient out of the stretcher into a position similar to that on a conventional operating table. Foam wedges may be used to change the position of the patient's head or legs. The confined space makes patient transfer almost impossible within the vehicle. Patients should be transferred to and from the operating stretcher just outside the vehicle. If the combat stretcher has not been adapted for surgery, patients may remain on the original stretcher for surgery and for evacuation afterwards. Access to the vehicle has to allow for a four-person lift of the loaded stretcher into the working cabin of the vehicle. Priority for the mobile operating room should be surgical service; casualty evacuation should proceed along regular lines. Performing surgery while on the move is likely to compromise the surgery and the move.
Secure, rapid evacuation, which has been a feature of recent wars, may not be available in future conflicts. Development of vehicles to support damage-control surgery in far-forward positions will be essential in such situations.

Acknowledgments: The authors are grateful for the expert help of David Beck, Matt Hudgins, Jamie Hersey and Rob Russell with elements of this report.

Affiliations: From the United States Navy (Leasiolagi, Holton); and the Canadian Forces Health Services (Doyle, Parkinson, Kao, McAlister).

Competing interests: None declared.

Contributors: All authors contributed substantially to the conception, writing and revision of this article and approved the final version for publication.

Disclaimer: The views expressed in this paper are those of the authors and do not constitute the views or policies of the Canadian Armed Forces.

\section{References}

1. Kotwal RS, Howard JT, Orman JA, et al. The effect of a golden hour policy on the morbidity and mortality of combat casualties. $7 \mathrm{AMA}$ Surg 2016;151:15-24.

2. Howard JT, Kotwal RS, Santos-Lazada AR, et al. Reexamination of a battlefield trauma golden hour policy. 7 Trauma Acute Care Surg 2018;84:11-8.

3. DaCambra MP, Kao RL, Berger C, et al. Utilization profile of the Canadian-led coalition Role 2 Medical Treatment Facility in Iraq: the growing requirement for multinational interoperability. Can 7 Surg 2018;61:S195-202.

4. Savage E, Forestier C, Withers N, et al. Tactical combat casualty care in the Canadian Forces: lessons learned from the Afghan war. Can 7 Surg 2011;54:S118-23.

5. Tien H, Beckett A, Garraway N, et al. Advances in damage control resuscitation and surgery: implications on the organization of future military field forces. Can 7 Surg 2015;58:S91-7.

6. Talbot M, Forestier C, Beck I. Far-forward surgery in the modern battlespace. Fournal of Military, Veteran and Family Health 2015;1:716. doi:10.3138/JMVFH.3206. Available: https://jmvfh.utpjournals. press/doi/pdf/10.3138/JMVFH.3206> (accessed 15 Aug 2018).

7. McAlister V. Somewhere in France (9 April 17): a centenary review of medical arrangements at Vimy Ridge. Can f Surg 2017;60:83-5.

8. Istl AC, McAlister VC. Western University (No. 10 Canadian Stationary Hospital and No. 14 Canadian General Hospital): a study of medical volunteerism in the First World War. Can 7 Surg 2016;59:371-3.

9. Hyatt AMJ, Geddes Poole N. Battle for Life. Waterloo (ON): The Laurier Centre for Military Strategic and Disarmament Studies; 2004. p 113.

10. WW2 US Medical Research Centre. WW2 US Army Ambulances and Medical-Related Vehicles. Available: www.med-dept.com/ articles/ww2-us-army-ambulances-and-medical-related-vehicles/ (accessed 2018 Aug. 15).

11. Pelczar K. Victory through logistics. United States Marine Corps; 2010 Available: www.1stmlg.marines.mil/News/News-Article-Display/ Article/543351/mobile-trauma-bay-brings-medical-care-closer-to -battlefield/ (accessed 2018 Aug. 15). 